\title{
ANTI-MARXISMO LATINOAMERICANO: EL CASO DE HERNÁN FAIR
}

\section{LATIN AMERICAN ANTI-MARXISM: THE CASE OF HERNÁN FAIR}

\author{
Roy Alfaro Vargas*
}

\author{
The philosophers have only interpreted \\ the world, in various ways; \\ the point is to change it. \\ Karl Marx (2000: 173)
}

\section{RESUMEN}

Este artículo es el producto de una reacción contra el anti-marxismo latinoamericano, especialmente contra la posición de Hernán Fair, quien arremete contra el marxismo desde una perspectiva que reproduce algunos estereotipos del periodo de la Guerra Fría. Asimismo, se critica la argumentación de Fair al considerarla altamente contradictoria y ligada a los intereses del actual neoliberalismo. Dentro del proceso de la crítica particular, se pasa a una crítica de las tendencias postmodernas y postestructuralistas, que nublan la visión sobre el verdadero compromiso de los intelectuales latinoamericanos y que implican asumir autores como Lacan, Derrida, entre otros, de manera poco reflexiva.

PALABRAS CLAVE: MARXISMO * ANTI-MARXISMO * POSTESTRUCTURALISMO *
POSTMODERNIDAD * POSTMARXISMO

ABSTRACT

This article is the product of a reaction against Latin American anti-marxism, especially against Hernán Fair's position, which attacks marxism from a perspective that reproduces some stereotypes of the period of Cold War. Also, I criticize the argumentation of Hernán Fair for considering it highly contradictory and linked to the interests of neoliberalism. In this process of criticizing Fair's position, I argue against the postmodern and poststructuralist trends that hide the vision of truly compromise from the Latin American intellectuals and imply to assume authors as Lacan, Derrida, etc., in an unthoughtful way.

KEYWORDS: MARXISM * ANTI-MARXISM * POSTSTRUCTURALISM * POSTMODERNITY * POSTMARXISM 


\section{INTRODUCCIÓN}

¡El marxismo ha muerto! ¡El fin de la historia ya llegó! Con la caída del capitalismo burocrático y la simbólica demolición del Muro de Berlín, la burguesía intelectual del Primer Mundo y la petite bourgeosie periférica (cada vez más unida al capital transnacional) corrían a celebrar su recién estrenada eternización. Suponían que el poder sería de ellos per sécula seculórum.

Así, los cuatro jinetes del Apocalipsis (Margaret Thatcher, Ronald Reagan, François Mitterrand y Mihail Gorbachov) montados sobre la ideología neoliberal y postmoderna, cabalgaban hacia lo que pretendían ellos, era el reino eterno del libre comercio. El reino de la luz nomocrática, donde todos podrían concurrir en el gran mercado global, donde la libertad del consumidor borraba del mapa al sujeto cognoscente, donde lo estético aplastaba la gnoseología y donde lo óntico (particular) anulaba, en la discontinuidad nietzscheana, cualquier ontología (de lo) posible. Mientras tanto, el judeo-cristianismo vendía a su dios y a sus fieles al mejor patrón.

La razón dejaba en este proceso, su espacio a la emoción (recordemos un claro ejemplo, la teoría de las inteligencias múltiples), el conocimiento del mundo, al autismo identitario; la continuidad cedía a lo discontinuo (el espacio absorbía el tiempo), la Differenz hegeliana se vestía pobremente como différance ${ }^{1}$ y el cuerpo (foco de la estrategia hedonista del consumismo) devenía el espacio probatorio, donde "mi" verdad explotaba en un baño de endomorfinas. El sujeto devino deseo, es decir, pene y vagina.

La racionalidad burguesa, a falta de un supuesto rival político, se convirtió metonímicamente en la razón par excellence. La

$1 \quad$ Así, "el capitalista tiene que movilizar cualquier relación social de diferencia, cualquier distinción dentro de la división social de trabajo, cualquier preferencia cultural especial o hábito, para prevenir la inevitable familiaridad en la posición dentro del lugar de trabajo, siendo esta consolidada en un movimiento de solidaridad social, y para sostener la fuerza de trabajo fragmentada y dividida" (Harvey, 2010: 104). (Esta y las siguientes traducciones de textos incluidos en la bibliografía en inglés, italiano o alemán, son propias del autor). ciencia, la tecnología y el conocimiento, en la versión burguesa, se satanizaron y con ello, todo lo racional. Se confundió de hecho, la racionalidad burguesa (la lógica del mercado que no mide las consecuencias) con la facultad de razonar que define al ser humano.

El animal del capitalismo ya no quería seres humanos, sino solamente animales libidinosos que (se) consumieran. Desde los años cincuenta del siglo xx, este animal se olvidó de producir y se enfocó en el consumir. La socialización se abocó a construir estructuras histéricas.

Sin embargo, a partir de los años 70 del siglo pasado, la Edad de Oro del capitalismo se desvaneció en el aire. Inflación, desempleo, violencia, bajo crecimiento económico, etc., fueron parte del diagnóstico de una enfermedad terminal: el capital ya no podría crecer y poco a poco, como todo sistema entrópico, este sería presa de Hades.

Hoy, a inicios del siglo XXI, este animal ya dio síntomas de una crisis sistémica. Sus órganos económicos ya no metabolizan el circuito de circulación-reproducción del capital y su sistema político se ha vuelto autoinmune (la democracia burguesa demuestra con fraudes electorales, asesinatos, corrupción y una completa intolerancia contra el pensamiento noburgués; que ya no hay reacción posible dentro del sistema capitalista).

A lo único que ha atinado este agonizante sistema, es a pregonar que el marxismo está muerto, porque el capital mismo sabe que sus mismas enfermizas y decadentes condiciones, son la energía que alimenta la superación del capitalismo propuesta por Marx.

Por todo lo anterior, se hace fundamental, en el contexto latinoamericano, comprender los verdaderos alcances del marxismo, los cuales se han tergiversado o simplemente, se han cambiado por una serie de clichés anti-marxistas, como en el texto de Fair (2010a) titulado "El debate político entre los enfoques marxistas, posmarxistas y posmodernos", publicado en la revista La Lámpara de Diógenes (México).

Ahora se procederá, en otro orden de cosas, a establecer cuál es la concepción del marxismo que maneja Fair, para luego, 
señalar cuáles son los fallos de tal planteamiento, dentro de un esfuerzo por determinar algunas contradicciones que se evidencian en el artículo mencionado anteriormente.

\section{EL MARXISMO SEGÚN HERNÁN FAIR}

Fair parte "de la base, junto con Marx, que toda acción implica necesariamente la necesidad de transformación radical de la sociedad" (2010a: 237). No obstante, el subsecuente desarrollo del artículo de Fair, muestra que ni se está con Marx, ni se busca una transformación radical de la sociedad. Esto es evidente cuando en la nota número uno, Fair indica que:

... hemos dejado a un lado a la izquierda marxista tradicional u ortodoxa, al entender que un proyecto de izquierda democrática sólo puede ser pensado alejado del extremismo y cerrazón que caracterizaron históricamente a este tipo de teorías, tanto en el plano teórico, como así también, y sobre todo, en la experiencia 'realmente existente' (en particular, durante la trágica experiencia estalinista) (2010a: 256).

Entonces, según Fair, hay un marxismo tradicional que él identifica con el estalinismo, el cual por su "carácter real" ha quedado descartado. Esto lleva a Fair a rechazar, primeramente, a través de un proceso metonímico, es decir, pasando la parte por el todo, el marxismo en general. En segundo lugar, esta posición lo lleva también hacia un supuesto marxismo noortodoxo, no-tradicional, mediante la asunción, vía Ernesto Laclau, de Antonio Gramsci.

El rechazar al marxismo viene unido a una crítica, poco o nulamente argumenta$\mathrm{da}$, de algunos conceptos gnoseológicos y de algunas concepciones económico-sociales del marxismo. En lo gnoseológico, Fair (2010a) dice que el marxismo - y Marx - tiene un concepto de "Verdad" (con mayúscula) que se establece como "una práctica totalizante, en el sentido de que buscaba abarcar todo el rango de posibilidades de la sociedad" (Fair, 2010a: 238). Para Fair, entonces, el marxismo es simplemente una teoría totalizante (palabra que en tal escrito debe leerse como totalitario) al modo del platonismo, del hegelianismo, del estructuralismo, del liberalismo, etc.

Por ende, según Fair, "en el marxismo, en cualquiera de sus variantes, existía la idea subyacente de que existía un centro o Verdad ontológica" (2010a: 242)2. Entonces, el marxismo, no el tradicional u ortodoxo, sino todas las formas de marxismo poseían (para continuar con el uso temporal de Fair) una noción de verdad propia de las teorías totalizantes, lo cual conduce a Fair a un "rechazo absoluto a la totalización de la teoría marxista" (2010a: 245).

En síntesis, en el aspecto gnoseológico, según Fair, el marxismo es una teoría totalizante que se ancla en una verdad ontológica (u ontologizante); es decir, substancializadora, la cual fija ciertos parámetros de una vez y por todas, aunque al inicio, concibe alguna forma de marxismo desconexa de las corrientes tradicionales, ortodoxas y estalinistas; al final, asume que todas las pretendidas formas de marxismo caen dentro de eso que él llama verdad ontológica y totalizante.

En el aspecto económico-social, siguiendo a Ernesto Laclau, Fair critica al marxismo (en todas sus variantes) "por defender un esencialismo económico y una noción de clase social que ya no tiene presencia ni posibilidad de aplicarse a la actualidad (más bien nunca la tuvo)" (2010a: 250). Ahora bien, el problema con la verdad del marxismo, según Fair, radicaba en que absolutizaba sus alcances (lo cual no cuestiona su validez, sino solo su extensión), pero, en lo económico-social, producto de las premisas epistemológicas del marxismo, los conceptos marxistas ya no solo son la sombra de una substancialización de la realidad, sino que nunca han sido válidos. Por ende, se puede deducir de lo dicho por Fair que la lucha política del marxismo también es inválida, lo cual quedó demostrado "a fines de los ochenta y comienzos de los noventa, con el fracaso de la perestroika y la restauración del capitalismo" (2010a: 240).

$2 \quad$ Es interesante que Fair en esta cita utilice el pasado imperfecto "existía", dando lugar a la idea de algo que recientemente ha dejado de existir. Recuerda la idea de la muerte del marxismo ( $y$ del fin de la historia, por tanto). 
Por consiguiente, Fair maneja una concepción del marxismo, que lo asume como un simple discurso, el cual es epistemológicamente inválido y socio-económicamente es inviable; olvidándose que él mismo ha operado un proceso de metonimización entre el estalinismo y el marxismo en general.

\section{CRÍTICA A LA CONCEPCIÓN FAIRIANA DEL MARXISMO}

Kant (2007) planteó en su Crítica de la razón pura, un sujeto activo, capaz de sintetizar a priori y dentro de un esquema lógico-formal, una verdad trascendental; es decir, universal $y$ necesaria. El sujeto kantiano, mediante el entendimiento, era la expresión de aquel sujeto nacido en el seno del auge de la burguesía y especialmente, ligado al Newton de los Principia. El sujeto kantiano era la expresión de un renacer de la filosofía entendida como teoría del conocimiento, donde el sujeto idealmente construía la cosa en sí.

Sin embargo, a pesar de la trascendentalidad de tal sujeto $y$ del avance filosófico que supuso el pensamiento marxiano, la posmodernidad se empeñaría en, según ella, destruir tal noción de subjetividad. Así, el sujeto de la Crítica de la razón pura, que ya había sido superado por Marx, se anula, por parte de los postmodernos, a favor del sujeto (también kantiano) de la Crítica del juicio.

El sujeto del juicio estético, del gusto, es el sujeto que pervive en y para la posmodernidad. ¡Sí, los posmodernos son más kantianos que Kant!

Kant decía que:

Para decidir si una cosa es bella o no lo es, no referimos la representación a un objeto por medio del conocimiento, sino al sentimiento de placer o de pena por medio de la imaginación (...). El juicio del gusto no es, pues, un juicio de conocimiento; no es por tanto lógico, sino estético, es decir, que el principio que lo determina es puramente subjetivo (2000: 33).

En otras palabras, si al estar yo con un amigo, veo una mujer pasar, yo podría enton- ces decir: "esa mujer es bella". Pero, mi amigo, no sin burlarse de mí, exclamaría: "esa mujer es no-bella (fea)". Luego, cómo podría ser tal mujer bella y fea a la vez. Para Kant, la respuesta es clara: la mujer no es ninguna de las dos cosas que se le atribuyen; simplemente, cada juicio expresa el sentimiento de placer o displacer experimentado por quien emite respectivamente cada juicio estético. Relativismo puro: dos juicios "válidos y contradictorios entre sí" para un solo y único objeto, a un mismo tiempo y espacio.

Sobre la montura de este sujeto estético, cabalga el anti-marxismo de Fair, pero no sin contradicciones, ya que si bien, el juicio anterior "esa mujer es bella" tiene una estructura similar a un juicio lógico, o sea, S es P; la verdad es que su contenido no tiene valor lógico, cognoscitivo, sino solamente emotivo. Es decir, como se verá, los juicios o argumentaciones de Fair son de carácter dóxico, simples opiniones, más que juicios con valor epistemológico; aunque Fair cree lo contrario.

De hecho, el esteticismo fairiano se manifiesta en su desmedido énfasis en el lenguaje, donde él tiene la creencia que "el discurso (...) es el lugar principal donde se realiza la lucha política" (Fair, 2010b: 3). Así, como el juicio estético de Kant no refería a objeto alguno, del mismo modo el lenguaje, según Fair, no refiere a una lucha efectivamente existente. Por tanto, el lenguaje autista es para Fair, autorreferencial o a-referencial, como se quiera ${ }^{3}$.

Según Fair, "algo que parece no entender el enfoque marxista (...) es la posibilidad ontológica que nos brinda el lenguaje de ser performativo" (2010a: 254). O sea, Fair supone que lo performativo hace del lenguaje una acción en sí misma. Dentro de la tradición lingüística, lo performativo "no solo describe la acción del hablante, sino que también ejecuta (performs) la acción misma" (Martin y Ringham, 2000: 100). Es decir, aquellos que se apegan a esta noción, dirían que el verbo prometer es performativo, ya que el prometer es en sí ya una

$3 \quad$ Fair olvida que "una discusión exclusivamente lingüística ("dialógica") es en principio infructuosa y podría ser continuada de manera indeterminada por mucho tiempo" (Kojève, 2002: 318). 
acción. Entonces la frase "prometo comportarme bien" sería en este caso, ya una acción completa; "nadie esperaría" que el complemento directo del verbo prometer, de esta oración, o sea, "comportarse" se haga efectivo (iqué se comporte mal, no importa!). A mi modo de ver, esto es absurdo, pero algunos lingüistas sostienen, aún hoy, que hay verbos performativos. Mas, Fair va aún más lejos y le otorga un valor performativo a todo el lenguaje. ¿Por qué?

La primera razón es su ligamen con Lacan (la segunda se irá viendo a lo largo del desarrollo de este artículo y es la fundamental). Para que el lenguaje sea performativo, es preciso eliminar la referencialidad del lenguaje, así como eliminar el complemento directo en el ejemplo anterior, con el fin de caracterizar el verbo prometer como performativo. Por ende, el lenguaje ya no refiere a algo real fuera de él, sino que "el orden significante, y el ejemplo primordial es la promesa, tiene la capacidad (siempre bajo ciertas condiciones) de performar una nueva realidad a partir de su simple enunciación" (Fair, 2010a: 254).

Aunque Fair nunca esgrime cuáles son esas condiciones en las que el lenguaje adquiere el poder de suplantar a la realidad, si se amarra a la idea derridiana de que "el ser es inseparable de la comprensión del ser" (Derrida, 1967: 144), ya que "la lucha de clases se realiza y adquiere sentido en la lucha cultural por la definición legitima de las palabras" (Fair, 2010b: 3$)^{4}$. De otra manera, la lucha de clases, al ser de tal, pasa por la comprensión de la relación entre significantes. No obstante, aquí hay una gran contradicción: ¿de qué manera podemos saber cuál definición de las palabras es la legítima? ¿No es cierto que ya Fair había eliminado el vínculo con lo real, con la referencialidad? y ¿sin referencialidad es posible discriminar entre dos o más opciones?

Entonces, sin base alguna para afirmar la legitimidad o la ilegitimidad de una construcción lingüística, que se supone "la definición legítima”, por qué Fair se amarra a la noción de performatividad. Porque para Fair, el lenguaje es performativo, un grupo de significantes que integran un sentido, cuando él lo utiliza

$4 \quad$ Énfasis propio. para comunicar su ilusión utópica, la de un mundo mejor construido a puro lenguaje. Pero, aquel otro que cuestionara su discurso, ese no emplearía un lenguaje performativo, a lo más, utilizaría un lenguaje homogeneizante. Fair reproduce la contradicción que cimenta toda la posmodernidad, o sea, un lenguaje que se pretende omnipotente, siempre y cuando lo use la derecha, los postmodernos. Sin embargo, Fair no se considera a sí mismo posmoderno, a pesar de que, como se va observando, tiene fuertes lazos con Derrida y Lacan.

Asimismo, Fair toma de Lacan la noción de lo real lacaniano, entendido como "el espacio de los fracasos de la simbolización, de lo no reprimible, de un en-sí incapaz de transformarse en para-nosotros" (Lacan, 1972: 58). En este sentido, lo real lacaniano es lo no-verbalizable, debido a que de lo real no se puede hablar, ya que de lo contrario, ya no sería lo real, sino lo simbólico. A lo real lacaniano, no hay ningún acceso. Es como la caja negra de los gestálticos.

Sin embargo, parece que Fair encontró la llave de tal caja. Para Fair, lo real es un límite para la objetividad, donde lo real "pese a ser ahistórico, se historiza bajo la forma de síntomas para ponerle límites (a la objetividad) y mostrar la imposibilidad de constitución plena" (2010a: 247). Mas, lo real lacaniano no es ahistórico, ya que si con el avance social se crean nuevas formas discursivas (para seguir la lógica implícita en Fair), entonces la relación entre lo simbólico y lo real sufre contraccionesexpansiones a través de la historia: se dejan de pronunciar algunos discursos y se crean otros nuevos. Lo que ya no se dice pasaría a formar parte del fracaso de la actual simbolización. Por lo tanto, lo real no es que sea ahistórico o histórico, más bien es un conjunto vacío (Ø), en cuanto es incognoscible.

Es decir, lo real no se puede definir en términos positivos. Lo real es lo no-imaginario y lo no-simbólico. No es percepción gestáltica del todo, ni discursable. Es matemáticamente un conjunto sin elementos, del cual Fair (siguiendo a Lacan) pretende crear algo nuevo, un nuevo conjunto, su ilusión utópico-lingüística.

La antinomia postmoderna es pretender crear algo de la nada. Por ejemplo, si tenemos 
el conjunto $\{1,2,3,4,5,6\}$, se podría derivar de este, el subconjunto de los números pares $\{2,4$, $6\}$, etc., pero del conjunto $\{\varnothing\}$, sin elementos, no se puede derivar ningún subconjunto. A pesar de esto, Lacan, Derrida y Fair creen que sí es posible derivar de la nada, algo. ¿De qué manera? Por medio de alguna forma de contrato social (de ideología) que subyace a tal proceso $y$ a ellos, indicando que tal nada en realidad es (entendida en este particular caso, como derivación de lo real lacaniano), aunque finalmente otra vez sea nada. Esto sería como plantear que los cimientos de un rascacielos son rígidos, que no tienen la flexibilidad requerida para ser los cimientos de este y aquel edificio a la vez, $y$ así con cada cimiento posible (es decir, con cada paradigma). Entonces, un día aparece un genial arquitecto que expresa que el conjunto cimiento será eliminado y cambiado por un conjunto vacío (sin cimientos). O sea, en lugar del cimiento no se pondrá nada y sobre esa nada, se alzará el edificio. ¡Yo personalmente no quiero, si todo esto fuera posible, subir a tal construcción! Nuevamente, así son los "cimientos" de la ilusión utópica de Fair y de toda la postmodernidad.

En estrecha relación con lo analizado, no es de extrañar entonces que Fair genere un concepto que solo es una formulación lingüística, un significante, o sea, el concepto de izquierda democrática. Tal concepto supone, en primer lugar, que hay una izquierda no-democrática, la cual correspondería, en el contexto de la propuesta de Fair, al marxismo. El problema con esto es que una izquierda excluyente, no sería izquierda (pero tampoco lo sería una que pretendiera solucionar todo), sería más bien derecha. O sea, el "socialismo ruso" no fue el proyecto de una izquierda, sino el de una derecha camuflada, que ocultó el capitalismo burocrático bajo un discurso pseudo-marxista, leninista-estalinista de hecho. En segundo lugar, y esto es lo peor, Fair quiere una izquierda que mantenga el ideario burgués de los derechos humanos:

El dilema, sin embargo, es cómo lograr esa transformación en el campo de la izquierda democrática sin dejar a un lado la defensa de los Derechos Humanos y los particularismos varios que han emergido en los últimos años y sin apartarse del todo de la fructífera e inacabada herencia marxista (Fair, 2010a: 247) ${ }^{5}$.

Evidentemente, Fair sigue extraviándose en su propio discurso. No solo los derechos humanos, tal y como se conciben hoy, son la expresión del individualismo burgués, sino que también empatar una cosmovisión anclada en el egoísmo, con una de corte social, colectiva, solo sería posible en el mero lenguaje. En la realidad (en sentido no-lacaniano), esto no pasa de ser una linda ilusión. Asimismo, es clara la contradicción entre estas dos cosmovisiones, la cual el mismo Fair no puede evitar sintomatizar. De hecho, en la cita anterior, Fair apela a "la fructífera e inacabada herencia marxista" (2010a: 247), cuando en otra parte de su texto, Fair indica que el marxismo (que en principio, recordemos, refiere al leninismoestalinista y luego generaliza a todo marxismo) "no tiene presencia ni posibilidad de aplicarse en la actualidad (más bien nunca la tuvo)" (Fair, 2010a: 250). El lector debe preguntarse, cómo va a recuperar Fair la verdaderamente fructífera e inacabada herencia marxista, si él mismo dice que no tiene valor alguno en la actualidad o más bien, puede el lector preguntarse por qué Fair entra en tan flagrantes contradicciones (las cuales finalmente dejan sin valor alguno su propuesta).

La argumentación de Fair responde a un esquema petit bourgeois; es decir, corresponde a los intereses del grupo dominante, que a partir de la crisis sistémica evidenciada desde el 2008, ha cambiado su discurso del fin de la historia $y$ de un marxismo muerto, por una crítica al pensamiento marxista, hoy en auge, a través de la reproducción de los prejuicios cacareados por Estados Unidos durante la Guerra Fría (y que hoy también lanza contra Venezuela y Cuba). Además, todo esto se debe a que Fair se enfoca, como ya se apuntó, en el lenguaje y en el significante, lo cual lo liga indisolublemente al estructuralismo y al postestructuralismo, ya que la noción de que "el lenguaje es fundamental para

$5 \quad$ Énfasis propio. 
la vida social es clave tanto para la teoría social estructuralista, como para la postestructuralista" (Chaffee, 2009: 73) y también debido a que "el postestructuralismo radicaliza la función del significante" (Chaffee, 2009: 83); tal y como lo hace Fair, al reducir todo a una cadena de significantes, de expresiones lingüísticas sin valor epistemológico o referencial. Con esto, Fair tampoco escapa a ser considerado un pensador postmoderno, en tanto que él reproduce una de las ideas fundamentales de la ideología postmoderna, o sea, "la atención al lenguaje $y$ al discurso" (Han, 2009: 117). Si el discurso postmoderno es un discurso fracturado $y$ fragmentario (Malpas, 2005: 5), entonces la evidencia apunta que el discurso de Fair es también postmoderno.

¿Por qué entonces Fair, postestructuralista y postmoderno, cree que él busca, junto a Marx, "la transformación radical de la sociedad"? (Fair, 2010a: 237).

Fair parte del enfoque postmarxista de Ernesto Laclau y Chantal Mouffe, quienes reasumen el concepto de hegemonía de Gramsci, con el fin de construir identidades contrahegemónicas, al mismo tiempo que rompen "la distinción entre objeto y contexto, prácticas discursivas y no-discursivas, o entre 'pensamiento y realidad"' (Goldstein, 2005: 55) ${ }^{6}$.

Claramente, Gramsci es leído en un contexto lacaniano, postestructuralista, postmoderno $y$ ahora postgramsciano. No obstante, los postmarxistas, que asumen a Gramsci y también a Althusser, reproducen un error que tergiversa de manera absoluta el contenido del pensamiento de Marx.

Gramsci y Althusser toman la unidad dialéctica de lo lógico y lo histórico, y la descomponen. Althusser desarrolla lo lógico (lo estructural), mientras Gramsci asumirá lo histórico ${ }^{7}$. Con el desmembramiento de

$6 \quad$ Al igual que Fair, este postmarxismo rompe la distinción entre prácticas discursivas y no-discursivas, simplemente anulando la (posibilidad de) existencia de prácticas no-discursivas, no-performativas, de la acción.

$7 \quad$ El lector puede profundizar en esta argumentación con el texto de Alfred Schmidt (1973) titulado Historia y estructura. esta unidad categorial dialéctica, se fundan dos corrientes que, gustosamente, la oficialidad académica, no sin algunos oscuros intereses, proclama marxistas: el althusserismo y el gramscismo.

Los postmarxistas, con sorpresa, asumen a uno u otro, o hacen una combinación de los aspectos de ambos que mejor les funcionan. Es usual que de Althusser se tome su rechazo al sujeto, con lo cual se trata, dentro de un contexto de inacción política anti-sistémica, de eliminar a cualquiera que se enfrasque en un cambio social o en la explicación científica de la realidad.

Gramsci apuntó hacia la acción, es decir, "Gramsci diseñó consistentemente su pensamiento para propósitos prácticos de la acción política" (Cox, 1983: 163). Sin embargo, una acción sin la adecuada reflexión de lo lógico, de lo estructural, es ciega. Entonces, de la noción de praxis transformadora del marxismo, se pasa a un estructuralismo inoperante, no-activo (en el caso del althusserismo) o a un activismo sin dirección alguna $y$ sin ningún conocimiento que guíe su accionar. Ni uno, ni otro son marxistas. De ahí que ambas propuestas (el énfasis en Althusser o en Gramsci) vengan a legitimar esta "novedosa" mercancía intelectual llamada postmarxismo. Mercancía que es un simple valor de cambio, donde el valor de uso ha prácticamente desaparecido. Esta mercancía solo quiere ser consumida, para nada desea insertarse en la cotidiana construcción de una historia sin clases sociales y lógicamente, sin la propiedad privada sobre los medios de producción.

Centrándose ahora en la propuesta de Fair, el cual siguiendo a Laclau, critica "que predeterminados estadios históricos o contextos económicos expliquen el desarrollo social" (Goldstein, 2005: 54). Más bien, "ellos asumen que la teoría postestructural puede trascender las divisiones y conflictos del moderno discurso político y de su contexto institucional, y exponer los antagonismos, dislocaciones o fisuras" (Goldstein, 2005: 65). Pero, si el postestructuralismo, como ya se mencionó, se asienta sobre el lenguaje, en el discurso, en el significante, entonces la propuesta Laclau-Fair no apunta realmente a resolver las divisiones y conflictos 
sociales, sino solamente a reformularlos lingüísticamente, con lo cual tal propuesta "permanece cómplice de la ideología dominante (de la burguesía)" (Goldstein, 2005: 61) ${ }^{8}$. Así, la propuesta no es marxista, sino subterfugiamente neoliberal: el hecho de no tocar el statu quo en el contexto actual, lo prueba.

Como en todos los actuales discursos sobre lo identitario, yace bajo ellos la defensa a ultranza del capitalismo y de la explotación de las clases bajas.

\section{3. ¿QUÉ ES EL MARXISMO?}

El marxismo es método, la aplicación del método dialéctico. Para el marxismo:

... el método que consiste en elevarse de lo abstracto a lo concreto es para el pensamiento sólo la manera de apropiarse lo concreto, de reproducirlo como un concreto espiritual. Pero esto no es de ningún modo el proceso de formación de lo concreto mismo (Marx, 1980: 22).

El marxismo, de hecho, parte de la aplicación de las categorías de lo abstracto y lo concreto, acercándose a lo concreto desde lo abstracto, en un proceso que obliga a superar nuevamente lo abstracto. Así, lo lógico debe ser abordado de tal modo que sea posible delimitar qué hay de real-concreto en ello. Entonces, la relación concreto-abstracto está mediada por la de lo lógico y lo histórico, en tanto que el pensamiento, dentro de una determinada formación social, con un determinado desarrollo científico-tecnológico y partiendo de la situación presente (concreta), regresa al pasado (no en un sentido genetista), buscando explicar las causas-efectos que cimentan el aquí y el ahora, para luego, mediante las categorías de lo real y lo posible, plantear algunos posibles futuros: esta es la negatividad. El marxismo, partiendo de lo real-concreto, devela el Ser para plantear el Deber Ser, la negación de la negación. Por ende, el socialismo aparece como la expresión práctica-posible (política) del capitalismo mismo, como una opción más entre muchos otros posibles.

$8 \quad$ Paréntesis propios.
Es claro que la aplicación, por parte de Marx, del método dialéctico al análisis de la economía, permitió a la dialéctica asumir un rol no solo en la interpretación del mundo social, sino en la transformación del mismo. El Deber Ser es política pura.

El marxismo es la asunción consciente del movimiento, de la entropía. En él, no hay espacio para absolutos, cuestión que no comprendió el leninismo-estalinista. Aquí no hay lugar para substancializaciones. El devenir siempre es una sucesión de contrarios, donde la discontinuidad siempre es superada por la continuidad: es la inserción del tiempo en el espacio. De ahí que el socialismo como posibilidad, no puede ser visto como un determinismo histórico, ya que "el determinismo histórico es una receta para el quietismo político" (Eagleton, 2011: 46) y el socialismo debe ser el producto de la acción consciente y constante del ser humano, de la especie, o sea, lo opuesto al quietismo político: "Marx no vio la historia como una evolución lineal" (Paolucci, 2007: 63), sino que él "vio el comunismo como un futuro potencial hecho posible por las bases materiales del capitalismo" (Paolucci, 2007: 5).

Dentro de este marco, siguiendo a Lefebvre (2011), la totalidad, como categoría filosófica $y$ en sus dos aspectos: la contradicción y la unidad, implica aceptar "que ninguna conclusión final para todo tiempo, lugar y circunstancia es posible o necesaria" (Paolucci, 2007: 72). Es decir, la categoría de totalidad es una salvaguarda contra el deseo de substancializar y esencializar cualquier proceso de carácter histórico y social. La totalidad es dinámica y no un espíritu del cual deviene lo concreto: "el hombre es totalidad" (Lefebvre, 2011: 114).

El socialismo se definirá como la síntesis dialéctica de la acción del sujeto histórico y de las de hoy, decadentes $y$ terminales condiciones del último capitalismo. Acción como negación de aquel discurso que, a su vez, la niega. Acción, no puro discurso, por cuanto "el discurso nada tiene de factual" (Lefebvre, 1967: 269).

\section{CONCLUSIONES}

La propuesta anti-marxista de Fair da al lenguaje poderes mágicos, aunque contrario 
a lo que él piensa, "El lenguaje no adquiere 'sentido' por el acto mágico de la relación entre significantes, sino por su inserción en la praxis" (Alfaro, 2009: 109). De hecho, el énfasis lingüístico de Fair es una cortina de humo (bastante común entre la derecha neoliberal) ante un panorama económico, práctico, real (en sentido no-lacaniano), no-discursivo que se define por una crisis sistémica, que al momento de escribir estas líneas, sintomatiza su profundidad en países como: Grecia, Portugal, etc. y que tanto la prensa, como algunos intelectuales, se dedican a invertir en una falsa conciencia colectivizada.

Hoy, algunos anti-marxismos latinoamericanos se visten con los ropajes del pseudo-marxismo de Althusser y Gramsci, con los imperativos de una falsa différance, queriendo reducir todo a lenguaje. Pero, también hoy: "Los conceptos básicos de Marx sobreviven a todas las críticas" (Harman, 2009: 53). Por eso, tratar a Marx con frases de burla como "Dios Marx" o "el genio de Marx" (Fair, 2010a: 252 y 254), no pasa de ser una argumentación ad hominem, que simplemente desconoce los aportes de un intelectual, sea uno marxista o no, que ha dejado una profunda huella en la humanidad; esto reafirma el deseo, existente en la propuesta de Fair, de desprestigiar al marxismo ${ }^{9}$.

En una Latinoamérica golpeada por la pobreza, la exclusión, el desempleo, el creciente empleo informal, etc. $y$ sangrada por las economías del Primer Mundo, con sus tratados del mal llamado libre comercio, tenemos condiciones suficientes $y$ necesarias para un cambio cualitativo; solo queda esperar que se generen los factores coyunturales detonantes, así como, la construcción de una voluntad colectiva que permitan un cambio cualitativo. En este contexto, la función del intelectual latinoamericano es generar conocimiento $y$ asimismo, crear los mecanismos de difusión de tal conocimiento, no desde la atalaya del academicismo, sino como un obrero (intelectual) más.

9 De hecho, "Marx desarrolló la concepción materialista de la historia, que desde entonces ha determinado, más de lo que quisieran admitirlo, hasta el modo de pensar de los no-marxistas y de los antimarxistas" (Löwith, 1971: 161).
Se debe sopesar que todos aquellos que hemos logrado acceder a la educación superior, disfrutamos de un privilegio que solo tiene el $1 \%$ de la población mundial; por lo que es ineludible compensar, el costo social que para cada uno de nosotros ha significado este privilegio. Por tanto, nuestro compromiso está con las grandes y explotadas masas que produjeron $y$ producen la riqueza que nos permite solo pensar y no con el parasitario narcisismo del intelectualoide de la academia, ni con el capitalista y menos aún, con el abultado salario.

Finalmente, el postestructuralismo postmoderno postmarxista y postgramsciano de Fair está postrado, sin ninguna posibilidad póstuma.

\section{BIBLIOGRAFÍA}

LIBROS

Chaffee, Daniel. "Structuralist and PostStructuralist Social Theory". The routledge companion to social theory. Anthony Elliot (ed.). Londres y New York: Routledge, 2009: 73-85.

Derrida, Jacques. L'écriture et la différance. Paris: Éditions du Seuil, 1967.

Eagleton, Terry. Why Marx was right. New Haven y Londres: Yale University Press, 2011.

Goldstein, Philip. Post-Marxist theory. An introduction. New York: State University of New York Press, 2005.

Han, Sam. "Postmodern social theory". The routledge companion to social theory. Anthony Elliot (ed.). Londres y New York. Routledge, 2009: 117-134.

Harman, Chris. Zombie capitalism. Global crisis and the relevance of Marx. Londres: Bookmarks Publications, 2009.

Harvey, David. The enigma of capital and the crises of capitalism. Londres: Profile Books, 2010.

Kant, Emmanuel. La crítica del juicio. México: Editores Mexicanos Unidos, 2000.

Kant, Emmanuel. Crítica de la razón pura. México: Taurus, 2007.

Lacan, Jacques. Las formaciones del inconsciente. Buenos Aires: Nueva Visión, 1972. 
Lefebvre, Henri. Lenguaje y sociedad. Buenos Aires: Proteo, 1967.

Löwith, Karl. Da Hegel a Nietzsche. La frattura rivoluzionaria nel pensiero del secolo XIX. Torino: Einaudi, 1971.

Malpas, Simon. The Postmodern. New York: Routledge, 2005.

Martin, Bronwen y Ringham, Felizitas. Dictionary of Semiotics. Londres y New York: Cassell, 2000.

Marx, Karl. Elementos fundamentales para la crítica de la economía política (Grundrisse). 1857-1858 Vol. I. México: Siglo XXI Editores, 1980.

Marx, Karl. "Theses on Feuerbach". Karl Marx. Selected writings. David McLellan (ed.). New York. Oxford University Press, 2000: 171-174.

Paolucci, Paul. Marx's scientific dialectics. A methodological treatise for a new century. Leiden, Holanda: Brill, 2007.

Schmidt, Alfred. Historia y estructura. Madrid: Alberto Corazón Editor, 1973.

REVISTAS

Alfaro Vargas, Roy. "Henri Lefebvre. Contrarréplica a George I. García". Revista de Ciencias Sociales 125 (III). Universidad de Costa Rica, 2009: 103-115.
Cox, Robert. "Gramsci, hegemony and international relations: an essay in method". Millenium: Journal of International Studies 12 (2). 1983: 162-175.

Fair, Hernán. "El debate político entre los enfoques marxistas, posmarxistas y posmodernos". La Lámpara de Diógenes 20-21. 2010a: 237-260.

Lefebvre, Henri. "La noción de totalidad en las ciencias sociales". Telos. Revista de Estudios Interdisciplinarios en Ciencias Sociales 13 (1). Universidad Rafael Belloso Chacín, 2011: 105-124.

Kojève, Alexandre. "Was ist Dialektik?". Deutsche Zeitschrift für Philosophie 50 (2). Berlin, 2002: 317-329.

\section{TEXTOS ELECTRÓNICOS}

Fair, Hernán. "La lucha de palabras es la (actual) lucha de clases". Razón y palabra 73. Instituto Tecnológico y de Estudios Superiores de Monterrey. Agosto-octubre 2010b: 1-8. En: <http:// www.razonypalabra.org.mx/N/N73/ Varia73/14Fair_V73.pdf> [consultado el 22 de mayo de 2011].

Fecha de ingreso: 30/06/2011 Fecha de aprobación: 11/07/2011 